\begin{tabular}{|c|c|c|c|c|c|c|c|}
\hline \multicolumn{3}{|l|}{ Case } & \multicolumn{2}{|c|}{ Onset of symptoms to ECMO initiationCT } & \multicolumn{2}{|c|}{ DADCT Total AbnormalitySOFA } & \multirow[b]{2}{*}{ CRP } \\
\hline \multirow[t]{2}{*}{ Number } & Diagnosis & Immunosuppression Regimen & Age (days) & $(\%)$ & $(\%)$ & Score & \\
\hline & Eosinophilic pneumonia; & & & & & & \\
\hline 1 & Hypereosinophilic syndrome & IVMP & 3021 & 100 & 82.5 & 7 & 344 \\
\hline 3 & Eosinophilic pneumonia & IVMP & 2612 & 0 & 80.0 & 9 & 285 \\
\hline 10 & Organising pneumonia & IVMP + CYC & 5230 & 10 & 66.8 & 12 & 226 \\
\hline \multirow[t]{2}{*}{11} & Acute interstitial pneumonitis & IVMP + RTX & $44 \quad 17$ & 100 & 88.8 & 11 & 497 \\
\hline & Anti-Jo 1 associated acute interstiti & & & & & & \\
\hline \multirow[t]{2}{*}{12} & pneumonitis & IVMP + CYC + RTX & $42 \quad 25$ & 10 & 82.1 & 11 & 350 \\
\hline & DD: AIP, eosinophilic pneumonia, & & & & & & \\
\hline 13 & Organising pneumonia & IVMP & 3519 & 90 & 91.7 & 13 & 266 \\
\hline \multirow[t]{2}{*}{ Mean } & & & 38.220 .7 & 51.7 & 82.0 & 10.5 & 328 \\
\hline & NON-RESPONDERS & & & & & & \\
\hline 2 & Acute interstitial pneumonitis & IVMP + CYC & $54 \quad 129$ & 88.4 & 68.4 & 6 & 70 \\
\hline \multirow[t]{2}{*}{4} & Idiopathic pleuropulmonary fibroelastosis & None & $45 \quad 140$ & 81.3 & 81.2 & 7 & 117 \\
\hline & Acute Interstitial pneumonitis; & IVMP + CYC + RTX plus heart & & & & & \\
\hline 5 & Organising pneumonia & transplant & $46 \quad 26$ & 50 & 85.9 & 9 & 153 \\
\hline 6 & Unclassifiable & IVMP + CYC + RTX & 2046 & 100 & 96.7 & 7 & 66 \\
\hline \multirow[t]{3}{*}{7} & Bleomycin-induced fibrosis & IVMP & $46 \quad 29$ & 82.5 & 85.8 & 9 & 111 \\
\hline & Clinically amyopathic & & & & & & \\
\hline & Dermatomyositis with acute interstiti & & & & & & \\
\hline 8 & pneumonitis & IVMP + RTX & $29 \quad 172$ & 100 & 95.6 & 4 & 71 \\
\hline Mean & & & $\begin{array}{ll}40 & 90.3\end{array}$ & 83.7 & 85.6 & 7.0 & 98 \\
\hline P-values & & & 0.790 .04 & 0.19 & 0.53 & 0.01 & 0.046 \\
\hline
\end{tabular}

Key: IVMP: Intravenous Methylprednisolone, RTX: Rituximab, CYC: Cyclophosphamide

score $(\mathrm{p}=0.01)$ and a lower preponderance of diffuse alveolar damage (DAD) on CT $(p=0.19)$ although there was no difference in overall extent of CT abnormality. (Table 1).

Conclusions The use of ECMO and early immunosuppression led to a $58.3 \%$ survival in a group of ILD associated SRF who would otherwise have been highly likely to die. The responders were characterised by a more acute and more inflammatory presentation. We suggest that ECMO and immunosuppression should be considered in patients with ILD and SRF who are failing mechanical ventilation.

\section{S10 COST BURDEN OF N-ACETYLCYSTEINE (NAC) IN ADULT PATIENTS WITH IDIOPATHIC PULMONARY FIBROSIS}

R Nasr, I Kausar, N Chaudhuri. InterMune UK\&I, London, UK

\subsection{6/thoraxjnl-2014-206260.16}

Introduction and objectives New data from the US IPFNET PANTHER Study ${ }^{1}$ has failed to demonstrate efficacy of NAC in adult IPF patients with mild to moderate disease. However, use of NAC in adults with Idiopathic Pulmonary Fibrosis (IPF) is commonplace in the $\mathrm{UK}^{2}$ despite weak clinical evidence and limited support from clinical guidelines. NICE recently estimated that between 30 and $45 \%$ of patients with moderate IPF are treated with NAC monotherapy at an annual cost of $£ 158$ per patient ${ }^{3}$. We wanted to estimate the cost burden of NAC prescribing in England based on the actual acquisition cost to the NHS.

Methods We obtained the actual prices of NAC at a dose of $600 \mathrm{mg}$ TDS from 11 different sources in England including IPF specialist centres, UK Medicines Information and guidance from Area Prescribing Teams and applied the average price into the NICE IPF costing template assuming $45 \%$ of moderate IPF (just over 3000 patients) patients receive NAC and 90\% are still taking treatment at 52 weeks.
Results The average annual cost of NAC from 11 different sources was $£ 675.63$ (425\% greater than NICE cost assumptions) with costs ranging from $£ 144-£ 1078$ per annum. This equates to an estimated annual cost of NAC in England of $£ 2,070,266$.

Conclusion NAC is unlicensed with a recent trial demonstrating limited benefit in treating IPF. The estimated annual cost burden of NAC to the NHS in England is very high. In light of the current financial position of the NHS more should be done to reduce the use of ineffective treatments that offer poor value for money. Physicians should re-evaluate the use of NAC in the management of IPF.

\section{REFERENCES}

1 Raghu $G$ et al The Idiopathic Pulmonary Fibrosis Clinical Research Nertwork. Randomized Trial of Acetylcysteine in Idiopathic Pulmonary Fibrosis. The New England Journal of Medicine 2014;370:2093-2101

2 Kausar et al. Practise Patterns in Idiopathic Pulmonary Fibrosis: Results of a UK Physician Survey. Thorax 2012;67:A117-A118 doi:10.1136/thoraxjnl-2012202678.411

(http://www.nice.org.uk/guidance/ta282/resources/ta282-idiopathic-pulmonary-fibrosispirfenidone-costing-template)

\section{S11 PIRFENIDONE POST-AUTHORISATION SAFETY REGISTRY (PASSPORT)-INTERIM ANALYSIS OF IPF TREATMENT}

${ }^{1} \mathrm{TM}$ Maher, ${ }^{2} \mathrm{~V}$ Cottin, ${ }^{3} \mathrm{M}$ Skoeld, ${ }^{4} \mathrm{~S}$ Tomassetti, ${ }^{5} \mathrm{~A}$ Azuma, ${ }^{6} \mathrm{C}$ Giot, ${ }^{6} \mathrm{D}$ Yocum, ${ }^{6} \mathrm{~S}$ Hamza, ${ }^{7}$ D Koschel. ${ }^{1}$ Interstitial Lung Disease Unit, Royal Brompton Hospital, London, UK; ${ }^{2}$ Louis Pradel Hospital, Lyon 1 University, Lyon, France; ${ }^{3}$ Karolinska Institutet, Stockholm, Sweden; ${ }^{4}$ GB Morgagni Hospital, Forli, Italy; ${ }^{5}$ Nippon Medical School, Tokyo, Japan; ${ }^{6}$ InterMune, Inc, Brisbane, United States; ${ }^{7}$ Fachkrankenhaus Coswig, Coswig, Germany

\subsection{6/thoraxjnl-2014-206260.17}

Introduction Pirfenidone (Esbriet ${ }^{\circledR}$ ) is approved for mild/moderate idiopathic pulmonary fibrosis (IPF). PASSPORT is a postauthorisation safety registry required by the European Medicine Agency.

Objective To present interim data from PASSPORT. 


\begin{tabular}{lllll}
\multicolumn{2}{l}{ Abstract S11 Table 1} & & \\
\hline & Patients & & All & All \\
& w/ADR & Patients & ADR & SADR \\
& $(\geq 10 \%)$ & w/SADR & Events & Events \\
\hline & $\mathrm{n}(\%)$ & $\mathrm{n}(\%)$ & $\mathrm{N}$ & $\mathrm{N}$ \\
Any ADR & $311(58.7)$ & $31(5.8)$ & 820 & 45 \\
Gl & $161(30.4)$ & $8(1.5)$ & 219 & 10 \\
Photosensitivity/ & & & & \\
Rash & $101(19.1)$ & $5(0.9)$ & 120 & 5 \\
Fatigue & $98(18.5)$ & $1(0.2)$ & 102 & 1 \\
Weight Loss & $56(10.6)$ & $4(0.8)$ & 60 & 4 \\
\hline
\end{tabular}

Method Up to $140 \mathrm{EU}$ sites will enrol 1000 patients. Safety data are recorded at routine clinic visits for 2 years. Adverse drug reactions (ADR: a noxious, unintended drug response at therapeutic doses) and serious ADRs (SADR: ADRs that are lifethreatening; cause death, disability, congenital anomaly; require hospitalisation or an intervention to prevent permanent impairment) are collected.

Results Data from 530 patients enrolled by 68 sites in 7 countries are included. Age was $69 \pm 8.8$ years (mean \pm SD); IPF diagnosis duration was $1.8 \pm 3.51$ years; $81 \%$ were men. Median time in study was 5.5 months; total exposure was 284 person-years.

Of 311 patients with ADRs, 85 discontinued due to ADR and 41 discontinued for other reasons. Approximately $1 / 3$ of patients with ADRs had their dose adjusted.

For patients who experienced an ADR:

- $55 \%$ of patients without a dose adjustment were able to continue treatment, while $69 \%$ of those with a dose adjustment were able to continue treatment.

- $20 \%$ discontinued due to the ADR after having a dose adjustment, but $31 \%$ discontinued due to the ADR without a dose adjustment.

When ADRs were managed by dose adjustment, dose adjustment was associated with continuing treatment.

Conclusion PASSPORT ADRs are comparable to those in clinical trials of pirfenidone in IPF. No new safety issues emerged. Dose adjustment may influence long-term tolerability of pirfenidone.

\section{S12 EFFECT OF BASELINE FVC ON DECLINE IN LUNG FUNCTION WITH NINTEDANIB: RESULTS FROM THE INPULSISTM TRIALS}

${ }^{1} \mathrm{U}$ Costabel, ${ }^{2} Y$ Inoue, ${ }^{3} \mathrm{~L}$ Richeldi, ${ }^{4} \mathrm{HR}$ Collard, ${ }^{5} \mathrm{~S}$ Stowasser, ${ }^{6}$ I Tschoepe, ${ }^{7} \mathrm{~A}$ Azuma. ${ }^{1}$ Ruhrlandklinik, University Hospital, University of Duisburg-Essen, Essen, Germany; ${ }^{2}$ National Hospital Organization Kinki-Chuo Chest Medical Center, Osaka, Japan; ${ }^{3}$ University of Southampton, Southampton, UK; ${ }^{4}$ University of California San Francisco, San Francisco, California, USA; ${ }^{5}$ Boehringer Ingelheim Pharma GmbH and Co. KG, Ingelheim Am Rhein, Germany; ${ }^{6}$ Boehringer Ingelheim France S. A. S., Reims, France; 'Nippon Medical School, Tokyo, Japan

\subsection{6/thoraxjnl-2014-206260.18}

Background Nintedanib, an intracellular inhibitor of tyrosine kinases, is in development for the treatment of idiopathic pulmonary fibrosis (IPF). The INPULSIS ${ }^{\mathrm{TM}}$ trials were two replicate randomised, double-blind, placebo-controlled, 52-week Phase III trials that assessed the efficacy and safety of nintedanib $150 \mathrm{mg}$ twice daily in patients with IPF. The primary endpoint was the annual rate of decline in forced vital capacity (FVC), which was significantly reduced in the nintedanib group compared with placebo in both trials.

Aim To assess the impact of baseline FVC on the effect of nintedanib on rate of decline in FVC.

Methods A pre-specified subgroup analysis of patients with baseline $\mathrm{FVC}>70 \%$ versus $\leq 70 \%$ of predicted value was undertaken using pooled data from both trials.

Results 700 patients (nintedanib 431, placebo 269) had baseline FVC $>70 \%$ predicted and 361 patients (nintedanib 207, placebo 154) had baseline FVC $\leq 70 \%$ predicted. For patients with a baseline FVC $>70 \%$ predicted, mean age was 67.4 years, $76.9 \%$ were male, $55.7 \%$ were White and mean carbon monoxide diffusion capacity $\left(\mathrm{DL}_{\mathrm{CO}}\right)$ was $4.0 \mathrm{mmol} / \mathrm{min} / \mathrm{kPa}$. For patients with a baseline $\mathrm{FVC} \leq 70 \%$ predicted, mean age was 65.5 years, $83.9 \%$ were male, $60.4 \%$ were White and mean $\mathrm{DL}_{\mathrm{CO}}$ was 3.6 $\mathrm{mmol} / \mathrm{min} / \mathrm{kPa}$. There was no significant treatment by subgroup interaction: the difference in adjusted annual rate of decline in FVC between the nintedanib and placebo groups was comparable in both subgroups.

Conclusion A subgroup analysis of pooled data from the INPULSIS $^{\mathrm{TM}}$ trials showed that nintedanib $150 \mathrm{mg}$ twice daily slowed the decline in lung function in patients with IPF, independent of severity of lung function impairment at baseline.

\section{Clinical management of lung infection}

\section{S13 INCIDENCE AND RISK FACTORS FOR THE DEVELOPMENT OF HOSPITAL ACQUIRED PNEUMONIA IN OLDER HOSPITALISED PATIENTS}

LA Burton, RJG Price, KE Barr, SM McAuley, JB Allen, A Clinton, G Phillips, CA Marwick, MET McMurdo, MD Witham. University of Dundee, Dundee, UK

\subsection{6/thoraxjnl-2014-206260.19}

Introduction and objectives Older people are at risk of hospitalacquired pneumonia (HAP). Few data exist on the incidence or risk factors for HAP in non-intensive care patients. Our aim was to determine the incidence and key risk factors for HAP in a sample of older people.

Methods A prospective survey of people $>65$ years admitted to Acute Medical, Medicine for the Elderly and Orthopaedic wards in NHS Tayside (Dundee, UK) over a 12 month period. HAP was defined in accordance with the European and Scottish National Prevalence Survey of Healthcare Associated Infection and Antimicrobial Prescribing, June 2011. Key analyses included: incidence of case-defined HAP, risk factors for development using Cox regression analysis and the percentage of clinically diagnosed HAP that met the diagnostic criteria for case-defined HAP.

Results A total of 1302 patients were included in the survey, 539 (41\%) male, and mean age 82 years (SD 8). Median length of hospital stay was 14 days (IQR 20). 157 episodes of HAP were suspected clinically in 143 patients (incidence 10.9\%), but only 83 episodes (53\% of total) in 76 patients met the diagnostic criteria (incidence 5.8\%). Case fatality rate was $29 \%$ in patients with confirmed HAP, and $19 \%$ in patients with suspected but not confirmed HAP. Risk of HAP increased by $0.3 \%$ per day spent in hospital. Swallowing problems were the single most important risk factor; HR 3.7 (95\% CI 2.2 to 6.1, p < 0.001).

Conclusion HAP is common but overdiagnosed in older hospitalised patients. Older patients with swallowing problems have a greater risk of developing HAP. Given the high mortality rate, 